\title{
Wettability of graphite by synthetic and industrial PGM-furnace matte
}

\section{(Molhabilidade por PGM-forno matte sintético e industrial)}

\author{
B. M. Thethwayo*, R. D. Cromarty \\ University of Pretoria, Centre for Pyrometallurgy, Department of Material Science and Metallurgy, \\ Pretoria, South Africa \\ *77mpilot@gmail.com,robert.cromarty@up.ac.za
}

\begin{abstract}
Wettability of SGL's RN-graphite by synthetic and industrial PGM (Platinum Group Metal)-furnace matte (CuFeNiS) was investigated using a sessile drop configuration. This work was done to determine the compatibility of a graphite refractory with liquid PGM-furnace matte. Direct measurements of interfacial contact angles were used to determine wettability. In inert conditions, graphite was poorly wetted by synthetic and industrial PGMfurnace matte (CuFeNiS), the contact angles were $>90^{\circ}$ for all tested matte types. No correlation was observed between the sulphur content of the matte and its wetting behaviour. The granulated matte expanded by up to 25 volume \% during melting.
\end{abstract}

Keywords: PGM matte, graphite wettability.

\section{Resumo}

A molhabilidade do grafite RN-SGL em forno-PGM de acabamento fosco (Cu Fe Ni S) sintético e industrial foi investigada usando uma configuração de gota séssil. Este trabalho foi feito para determinar a compatibilidade de um refratário de grafite com líquido PGM-forno de acabamento fosco. Medidas diretas de ângulos de contato interfacial foram usadas para determinar a molhabilidade. Em condições inertes, grafite foi levemente molhado pelo PGM-forno de acabamento fosco (Cu Fe Ni S) sintético e industrial, os ângulos de contacto foram $>90^{\circ}$ para todos os tipos de matte testados. Não houve correlação entre o teor de enxofre do acabamento fosco e seu comportamento molhamento. O acabamento fosco granulado foi expandido em até $25 \%$ em volume durante a fusão.

Palavras-chave: acabamento fosco, metais do grupo platina, molhabilidade do grafite.

\section{INTRODUCTION}

Application of graphite is a recent development in the refractory-wall design of Platinum Group Metals' (PGM) smelters. Consequently, not much data are available on the behaviour of graphite when it is exposed to liquid PGMfurnace matte. Graphite-blocks are currently used as a barrier between the coppercoolers and the furnace melt at the upper side-wall (feed and slag level) of the PGM smelter [1]. Graphite has improved the integrity of the furnace lining in the slagfeed tidal zone. It is envisaged that using graphite at the matte-zone might improve the overall service life of the refractory lining of the PGM smelter. This work aims to determine the wettability of RN-graphite by PGM-furnace matte. Wettability is the initial step in assessing the compatibility of graphite with liquid PGM-furnace matte, subsequent work will focus on determining the resistance of graphite to penetration and dissolution by matte. The experiments performed aim to address the following research question: Does a PGMfurnace matte $(\mathrm{Cu}-\mathrm{Fe}-\mathrm{Ni}-\mathrm{S})$ wet $\mathrm{RN}$-graphite?

For in depth study of refractory wear, it is initially required to understand the mechanism of wetting when refractory material is in contact with the liquid [2]. Wetting can be classified into physical wetting and chemical wetting [3]. In physical wetting, reversible physical forces (van der Waals and dispersion) provide the attractive energy required to wet the surface. In chemical wetting, the reaction occurring at the solid-liquid interface is
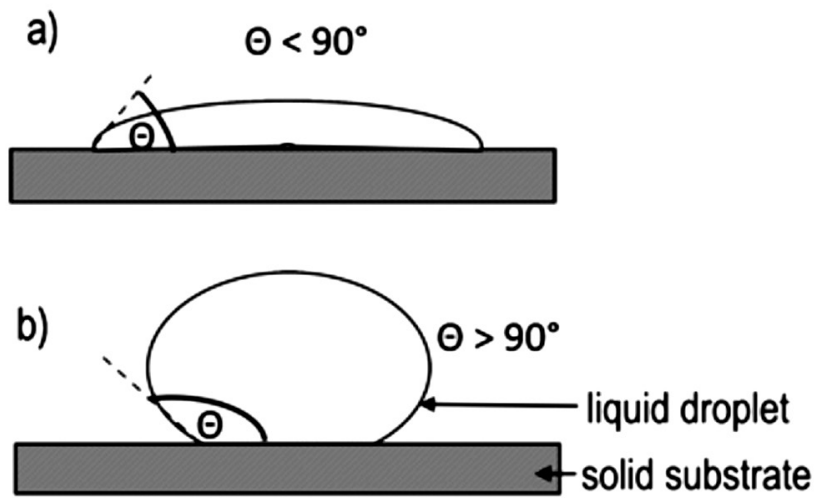

Figure 1: Schematic illustration of the sessile drop configuration (a) contact angle $<90^{\circ}$ (wetting system), (b) contact angle $>90^{\circ}$ (non-wetting system) [5].

[Figura 1: Ilustração esquemática da configuração de gota séssil (a) ângulo de contacto $<90^{\circ}$ (sistema de molhagem), (b), ângulo de contacto $>90^{\circ}$ (sistema não molhável) [5].] 
responsible for wetting $[3,4]$.

A contrast between the wetting system and the nonwetting system is shown in Fig. 1 (sketches taken from [5]). By definition, when the interfacial angle between a substrate and liquid droplet is $\angle 90^{\circ}$, the liquid wets the solid (Fig. 1a) and when the interfacial angle between the substrate and liquid is $>90^{\circ}$, the solid is non-wetted by the liquid (Fig. 1b) $[4,5]$. The contact angle $\theta$ is an accepted measure of wettability in relation to a liquid droplet on a solid surface [4].

\section{MATERIALS AND METHODS}

Scanning electron microscopy (SEM), X-ray fluorescence (XRF), X-ray diffraction (XRD) and electronprobe micro analyser (EPMA) were used to analyse the materials.

\section{$R N$-graphite}

The RN-graphite used was an extruded synthetic graphite acquired from SGL, its properties are shown in Table I. This graphite is a typical graphite grade used at a hot-face of the upper side-wall of an industrial PGMsmelter refractorylining. Graphite samples were ground polished to a smooth and flat surface using a 600-grit SiC-paper. To prevent contact-angle hysteresis (errors or variations in contact angle), the substrate surface has to be flat, homogenous and smooth [2].

Table I - Properties of RN-graphite.

[Tabela I - Propriedades do grafite-RN.]

\begin{tabular}{ccc}
\hline Property & units & Values \\
\hline Apparent density & {$\left[\mathrm{g} \cdot \mathrm{cm}^{-3}\right]$} & 1.62 \\
Porosity & {$[\%]$} & 24 \\
Permeability & {$\left[\mathrm{cm}^{2}\right]$} & $9.1 \times 10^{-10}$ \\
Pores $\leq 10 \mu \mathrm{m}$ & {$[\%]$} & 70 \\
Pores $\geq 50 \mu \mathrm{m}$ & {$[\%]$} & 5 \\
Thermal conductivity & {$\left[\mathrm{W} \cdot \mathrm{K}^{-1} \cdot \mathrm{m}^{-1}\right]$} & 150 \\
Machining & & Extruded \\
\hline
\end{tabular}

PGM furnace-matte

The matte types tested in this work are the following: Synthetic matte [Matte-S], Lonmin (industrial matte) [Matte-L] and Amplats Waterval-smelter (industrial matte) [Matte-A].

\section{Synthetic matte (Matte-S)}

Matte-S was prepared from sulfide powders acquired from Sigma-Aldrich. The mixture used to form synthetic matte had 12 wt.- $\% \mathrm{Cu}_{2} \mathrm{~S}, 66$ wt.- $\% \mathrm{FeS}$ and 22 wt.-\% $\mathrm{Ni}_{3} \mathrm{~S}_{2}$. The sulphide-mixture was loaded into an alumina crucible and heated for one hour at $1100{ }^{\circ} \mathrm{C}$ in a verticaltube furnace. The molten sulphide-mixture was slow cooled and analysed to verify its composition. Matte-S had 62 wt.- $\%$ (FeNi) ${ }_{9} \mathrm{~S}_{8}, 36$ wt.- $\% \mathrm{FeS}$ and 2 wt.- $\% \mathrm{CuFeS}_{2}$ according to the XRD analysis.

\section{Industrial PGM-furnace matte [Matte-A and Matte-L]}

Industrial PGM-furnace matte was acquired from two South African PGM producers, namely; Amplats (Waterval smelter) and Lonmin (no.1) smelter. Amplatsmatte (Matte-A) was granulated during tapping whereas Lonmin-matte (Matte-L) was slow cooled after tapping. Matte-A and Matte-L had similar XRD patterns, the average XRD quantitative analysis for both mattes had 59 wt.$\%$ (FeNi) ${ }_{9} \mathrm{~S}_{8}, 29$ wt.- $\% \mathrm{FeS}, 3$ wt.- $\% \mathrm{CuFeS}_{2}$ and 9 wt.-\% amorphous material. The composition of the amorphous material was acquired by EPMA. Iron-chrome oxide and silicates of $\mathrm{Al}, \mathrm{Ca}, \mathrm{Fe}, \mathrm{Mg}$ and $\mathrm{Na}$ were detected as major phases in the impurities in as-received matte-A. Matte-L had iron chrome oxide as a major impurity; silicates were not detected in Matte-L. The silicates and oxides report to the slag phase during industrial PGM matte smelting [6]. The oxide phases detected in industrial matte could result from slag entrainment in matte, poor separation between the slag and matte or high solubility of slag phases in matte which are typical phenomenon during the PGM matte smelting process [6]. The silicates are typically amorphous material, hence XRD could not accurately detect the phases in the impurities.

Matte was subjected to XRF to confirm its elemental composition, the XRF analysis is depicted in Table II. The proportions of metals $(\mathrm{Co}, \mathrm{Cr}, \mathrm{Cu}, \mathrm{Fe}$ and $\mathrm{Ni}$ ) in Matte-A, Matte-L and Matte-S are comparable. Sulfur content of Matte-A is relatively low (20.8 wt.- $\%$ ) when compared to that of Matte-L and Matte-S. Matte-A also has appreciable amounts of impurities such as $\mathrm{Al}, \mathrm{Ca}, \mathrm{Mg}$ and $\mathrm{Si}$ as detected by EPMA. The presence of these elements in industrial matte confirmed the presence of slag-mpurities in asreceived industrial matte. Matte was tested as-received; no purification was done on the matte samples.

Table II - Elemental composition of Matte-A, Matte-L and Matte-S by XRF (wt.\%).

[Tabela II - Composição elementar da Matte-A, Matte-L e Matte-S por FRX (peso\%).]

\begin{tabular}{lcccccccccc}
\hline & $\mathrm{Fe}$ & $\mathrm{S}$ & $\mathrm{Ni}$ & $\mathrm{Cu}$ & $\mathrm{Si}$ & $\mathrm{Mg}$ & $\mathrm{Cr}$ & $\mathrm{Al}$ & $\mathrm{Co}$ & $\mathrm{Ca}$ \\
\hline Matte A & 44.5 & 20.8 & 16.4 & 10.7 & 3.0 & 1.6 & 1.1 & 0.8 & 0.7 & 0.4 \\
Matte L & 44.7 & 27.3 & 15.7 & 9.3 & 0.1 & 0.0 & 1.7 & 0.5 & 0.6 & 0.2 \\
Matte S & 45.7 & 26.3 & 16.2 & 11.0 & 0.1 & 0.2 & 0.1 & 0.2 & 0.1 & 0.1 \\
\hline
\end{tabular}

\section{Apparatus}

Wettability tests were done in a Coal Ash Fusion (CAF) furnace using a sessile drop method. A CAF furnace is a horizontal tube furnace which is heated using $\mathrm{SiC}$ heating elements. The furnace work-tube is made of sintered alumina, it has an inside diameter of $80 \mathrm{~mm}$. The work-tube 
is fitted with stainless steel flanges at both ends. The gas inlet and outlet ports are fitted on the flanges. The furnace temperature is controlled and measured using a B-type thermocouple placed inside the furnace tube at the hot zone. The CAF furnace is fitted with a digital camera to enable image capturing; a camera is connected to a computer which stores the images with a corresponding time and temperature. A schematic diagram of the CAF experimental set-up is shown in Fig. 2. CAF furnace was used because it was readily available and is equipped to take images of the specimen during the experiment.

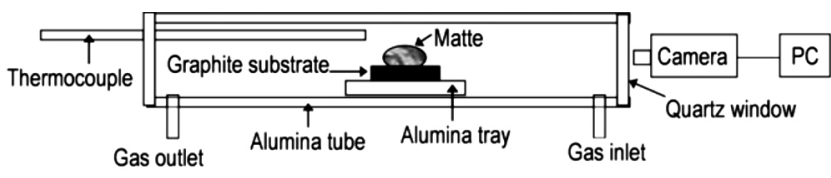

Figure 2: Schematic diagram of the CAF furnace setup.

[Figura 2: Diagrama esquemático da configuração do forno CAF.]

\section{EXPERIMENTAL PROCEDURE}

Sessile-drop method is commonly used for determination of wettability [5]. In a sessile-drop method the material is shaped and placed on the surface of the substrate $[2,5,7]$. The specimen is heated to the operating temperature and the interfacial contact angle between the molten droplet and the solid substrate is measured [5].

Matte samples were milled to below $150 \mu \mathrm{m}$ before pelletizing. Average particle size-distribution of matte was as follows, $\mathrm{D} 10=5.8 \mu \mathrm{m}, \mathrm{D} 50=12.4 \mu \mathrm{m}$ and D90 $=47.7$ $\mu \mathrm{m}$. Matte powder was formed into cylindrical pellets using a press and die. A typical pellet was $10 \mathrm{~mm}$ outside diameter and $\pm 5 \mathrm{~mm}$ in height. A typical specimen setup is depicted in Figure 3. A matte-pellet was placed on an RN-graphite block (20 mm x $20 \mathrm{~mm} \times 5 \mathrm{~mm})$ as shown in Fig. 3. The specimen was pushed into the hot zone of the furnace at the beginning of the test. The furnace temperature was raised

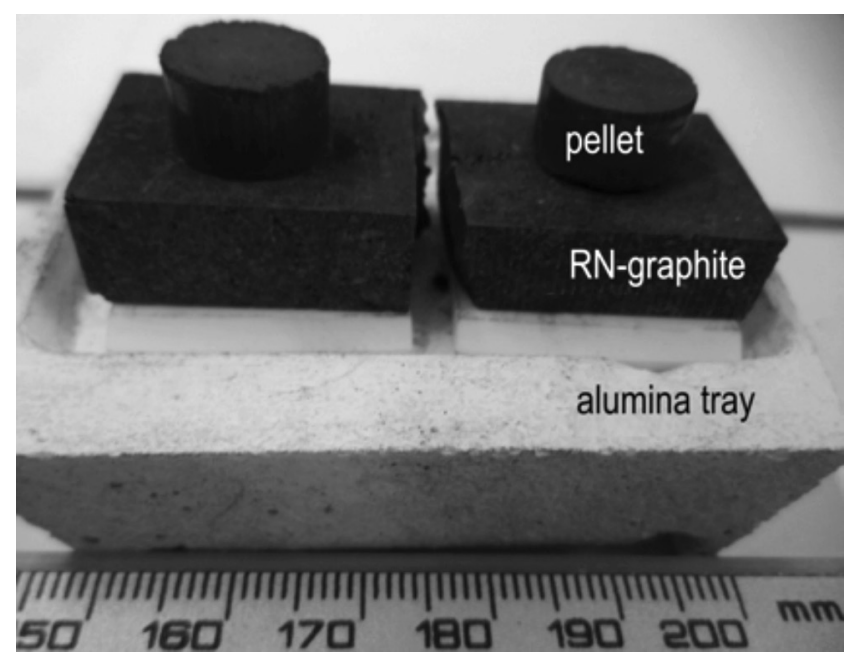

Figure 3: Wettability tests specimen setup.

[Figura 3: Montagem das amostras para testes de molhabilidade.] to $1350{ }^{\circ} \mathrm{C}$ at $7{ }^{\circ} \mathrm{C} / \mathrm{min}$, the highest operating temperature was limited to $1350{ }^{\circ} \mathrm{C}$ to prevent possible damage to the CAF furnace. The furnace was continuously purged with high-purity argon to maintain inert atmosphere inside the furnace. During the experiment, the furnace camera was set to capture an image of the specimen every $10{ }^{\circ} \mathrm{C}$ starting from $650{ }^{\circ} \mathrm{C}$, the last image was taken at $1350{ }^{\circ} \mathrm{C}$, when possible.

The softening and melting temperatures of the pellets were recorded manually using the captured images. The temperature at which the pellet shape started deforming was taken as softening temperature. The temperature at which the pellet became spherical was taken as the melting temperature. Graphite wettability was determined by direct measurement of interfacial contact angle between the molten matte and the graphite substrate. Contact angles were measured from the images captured by the camera during the experiments. The contact angle considered was the angle formed immediately after the droplet was fully molten to minimise errors associated with long contact time.

\section{RESULTS AND DISCUSSION}

The recorded wetting angle, softening temperature and melting temperature for all the experiments are shown in Table III. The melting temperature for Matte-A was not recorded because Matte-A pellet rolled off the substrate before it was fully molten. Images corresponding to the softening and melting temperatures are depicted in Figs. 4 to 6 for respectively Matte-S, Matte-L and Matte-A.

Table III - Contact angle, softening and melting temperatures of matte.

[Tabela III - Angulo de contato, temperaturas de amolecimento e de fusão do material.]

\begin{tabular}{lccc}
\hline \multirow{2}{*}{ Material } & \multirow{2}{*}{$\begin{array}{c}\text { Contact angle } \\
\theta\left({ }^{\circ}\right)\end{array}$} & \multicolumn{2}{c}{ Melting temperature $\left({ }^{\circ} \mathrm{C}\right)$} \\
\cline { 3 - 4 } & $113 \pm 3$ & Softening & Melting \\
\hline Matte-S & 1120 & 1070 \\
Matte-L & $126 \pm 7$ & 950 & 1020 \\
Matte-A & $147 \pm 7$ & 850 & $\ldots$ \\
$\begin{array}{c}\text { Matte-A } \\
\text { residue }\end{array}$ & 35 to 120 & 1260 & 1350 \\
\hline
\end{tabular}

The interfacial contact-angles between graphite and Matte-S, Matte-L and Matte-A were respectively $113^{\circ}, 126^{\circ}$ and $147^{\circ}$. Graphite was poorly wetted by synthetic and industrial PGM-furnace matte because a contact angle of greater than $90^{\circ}$ (between liquid droplet and solid substrate) indicates poor wettability $[4,5]$.

Matte-S started softening at $920{ }^{\circ} \mathrm{C}$ and was molten at $1070{ }^{\circ} \mathrm{C}$, the images from softening to melting are depicted in Fig. 4. Matte-S initially spread on the graphite surface before the spherical droplet was formed. The volume of MatteS remained constant during and after melting. The molten droplet rolled off the substrate above $1200^{\circ} \mathrm{C}$. 
Matte-L started softening at $950^{\circ} \mathrm{C}$ and it appeared molten at $1020^{\circ} \mathrm{C}$. The images of Matte-L pellet from softening to melting are depicted in Fig. 5. The volume of the droplet remained constant during melting, after melting it started decreasing with increasing temperature. The decrease of the droplet of Matte-L could be attributed to the evaporation of gaseous species from the droplet owing to long exposure time and increase in temperature as explained by Luz et al. 2008 [2]. Adsorption of the species of the droplet on the surface of the substrate is another factor that can cause a decrease in the volume of the droplet as discussed by Bruce et al. 2005 [8]. The graphite substrate did not have any adsorbed matte species after exposure, therefore the evaporation of volatile species is a probable mechanism which lead to a decrease in the volume of Matte- $\mathrm{L}$ droplet. Matte-L droplet became unstable with temperature, it rolled off the graphite substrate at $1290{ }^{\circ} \mathrm{C}$.

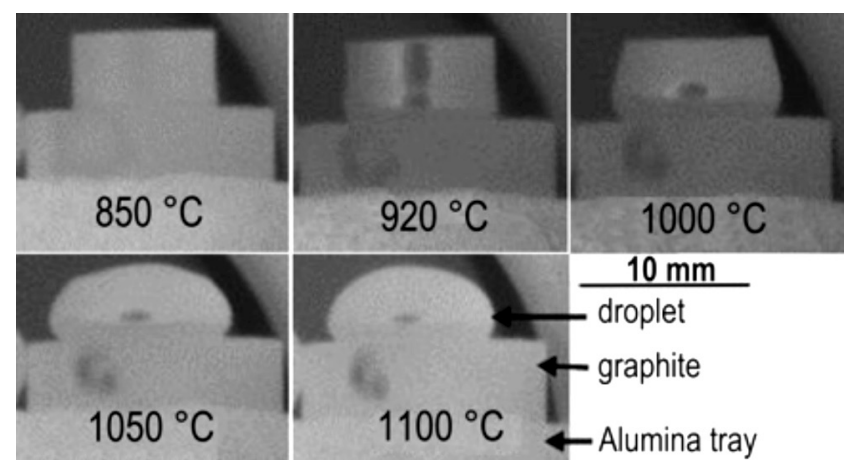

Figure 4: Matte-S droplet on graphite-substrate $\left(850^{\circ} \mathrm{C}\right.$ to $\left.1100^{\circ} \mathrm{C}\right)$. [Figura 4: Gota de Matte-S no substrato de grafite $\left(850^{\circ} \mathrm{C}\right.$ a $\left.\left.1100^{\circ} \mathrm{C}\right).\right]$

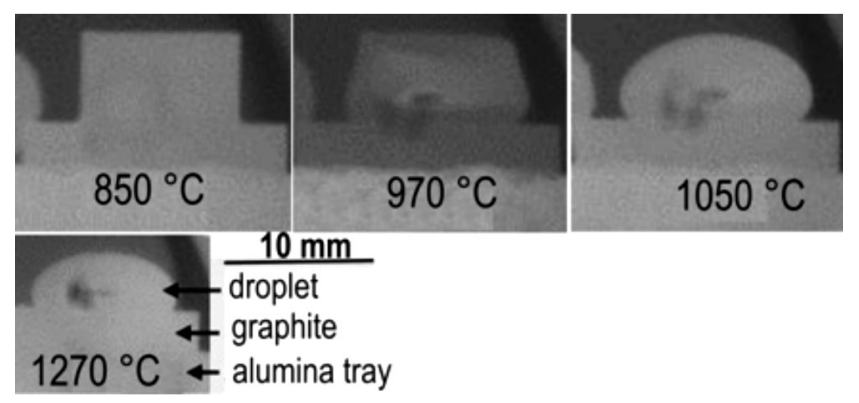

Figure 5: Matte-L droplet on graphite-substrate $\left(850^{\circ} \mathrm{C}\right.$ to $\left.1270^{\circ} \mathrm{C}\right)$. [Figura 5: Gota de Matte-L no substrato de grafite $\left(850^{\circ} \mathrm{C}\right.$ a $\left.\left.1270{ }^{\circ} \mathrm{C}\right).\right]$

Matte-A softening and melting images are shown in Fig. 6. Matte-A started softening at $850{ }^{\circ} \mathrm{C}$, it formed a very sharp contact-angle with graphite (Fig. 6 Matte-A $970{ }^{\circ} \mathrm{C}$ ). Significant increase in the volume of the droplet was observed during softening. ImageJ software measured $25 \%$ increase in the volume of the Matte-A droplet.

Increase in Matte-A volume can be attributed to the formation of gaseous species associated with melting. Siddiqi and co-workers [4] studied graphite-slag wetting, they observed that the inflation of the droplet during wetting tests is caused by the formation of gaseous products. In their

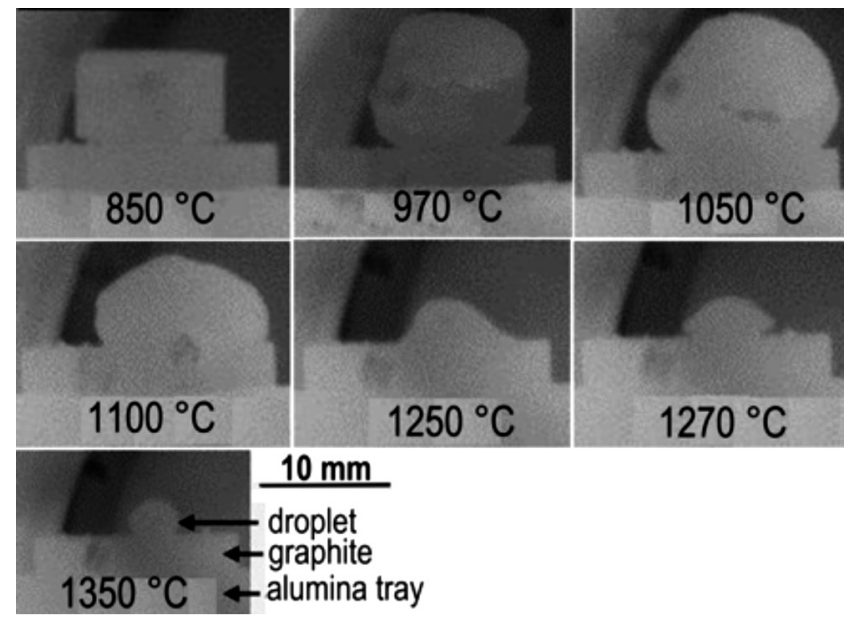

Figure 6: Wettability of RN graphite by Matte-A $\left(850{ }^{\circ} \mathrm{C}\right.$ to $\left.1350{ }^{\circ} \mathrm{C}\right)$.

[Figura 6: Molhabilidade do grafite $R N$ por Matte- $A\left(850{ }^{\circ} \mathrm{C}\right.$ a $\left.\left.1350^{\circ} \mathrm{C}\right).\right]$

work they observed that when the gas is generated it inflates the volume of the droplet, the inflated volume is retained until the gas escapes the droplet [4]. Bhoi and coworkers [3] also observed the inflation of the droplet as a result of the gas trapped in the droplet during the wettability tests. The Matte-A pellet rolled off the graphite block at $1100{ }^{\circ} \mathrm{C}$, before it was fully molten. The droplet falling was gradual and the material seemed very sticky. The increase of the volume of the pellet possibly enhanced the instability of the pellet which then caused the pellet to fall. The repulsion (lack of adhesion) between Matte-A and graphite is evinced by the sharpness of the interfacial contact-angle, this could also influence the instability and falling of the pellet.

A small heap of material remained on top of the graphite after the bulk of the matte had fallen off (Fig. 6, Matte-A $1250{ }^{\circ} \mathrm{C}$ ). The matte-residue had a contact angle of $30^{\circ}$ to $50^{\circ}$. At $1230^{\circ} \mathrm{C}$ the volume of the matteresidue started increasing. Matte-residue appeared molten at $1350{ }^{\circ} \mathrm{C}$, it formed a contact-angle of $120^{\circ}$ with graphite. The composition of the matte-residue was determined by EPMA. The major phases in the matte-residue were silicates of $\mathrm{Fe}-\mathrm{Ca}, \mathrm{FeMg}$ and the oxides of $\mathrm{Cr}$ and $\mathrm{Fe}$, these phases were similar to the slag-impurities detected on as-received Matte-A. Minor amounts of sulfide phases were detected in the Matte-A residue, this indicates that when the mattedroplet fell off the substrate, some matte was trapped in the slag-impurities. The liquidus temperature of a typical PGMfurnace matte is $850^{\circ} \mathrm{C}$ to $875^{\circ} \mathrm{C}$, whereas that of slag is $1350{ }^{\circ} \mathrm{C}[6]$. This explains why the slag-impurities melted at $1350{ }^{\circ} \mathrm{C}$ whereas the matte started softening at $850^{\circ} \mathrm{C}$.

The difference in behavior [wetting angle, volume change, spreading and repulsion] of the tested matte types indicates that; melting and wetting behavior of sulfides is specific to the composition of the aliquot sample. The matte had comparable amounts of base metal sulfides but the behavior of each matte is unique. As such, the behavior of matte cannot be generalized; impurities in matte seem to have major effect in its melting and wetting behavior. 
Adding surfactants such as sulfur to a metal or compound lower the surface tension of that metal or compound [9]. The metal to sulfur ratio of matte did not affect the wetting angle between the matte and graphite. Matte-S had a lower sulfur content than Matte-L but Matte-S had a lower wetting angle $\left(113^{\circ}\right)$, than that of Matte-L $\left(126^{\circ}\right)$. The effect of sulfur content on the wetting behavior of Matte-A cannot be conclusive because the slag-impurities in Matte-A possibly had significant effects on the melting and wetting behavior of Matte-A. Further work is needed to assess the effect of each element ( $\mathrm{Al}, \mathrm{Ca}, \mathrm{Mg}, \mathrm{S}, \mathrm{Si}$ and $\mathrm{O}$ ) on the melting and wetting behavior of matte.

The instability of the droplet with increase in temperature was observed in this work, all the droplets rolled off the graphite-substrate after melting. The instability of the droplet could be attributed to the change in its viscosity, which is envisaged with increase in temperature [2].

Graphite consumption by matte could not be quantified because the matte-droplets and the process gas could not be analysed. However, no measurable change in the dimensions of the graphite-substrate was observed after exposure.

Penetration and dissolution of a refractory is enhanced by good wetting and chemical reactivity [10]. Since graphite is poorly wetted by matte, penetration of liquid matte through a graphite crucible is not envisaged. However, current work did not consider external factors such as change in system pressure or turbulence in the system.

\section{CONCLUSIONS}

$\mathrm{RN}$-graphite is poorly wetted by synthetic and industrial PGM-furnace matte (Cu-Fe-Ni-S) based on the observed wetting angle. The penetration and dissolution of graphite by synthetic and industrial PGM-furnace matte is not envisaged where a graphite crucible is exposed to liquid matte. Diverse melting and wetting behavior amongst the tested matte type was observed, the behavior of each matte type (synthetic or industrial) is unique to that specific matte (composition and impurities).

\section{ACKNOWLEDGMENTS}

Authors would like to thank Anglo American Platinum and Lonmin for financial and technical support, SGL for supplying graphite. "This work is based on the research supported in part by the National research Foundation of South Africa (Grant number TP1208219517)".

\section{REFERENCES}

[1] P. K. van Manen, $3^{\text {rd }}$ Int. Plat. Conf. 'Platinum in Transformation', Sun City, SA, SAIMM (2008) 191-196.

[2] A. P. Luz, S. Ribeiro, V. C. Pandolfelli, Cerâmica 54 (2008) 174-183.

[3] B. Bhoi, H. S. Ray, V. Sahajwalla, J. Inst. Eng. (India), 89 (2008) 3-8.

[4] N. Siddiqi, B. Bhoi, R. K. Paramguru, V. Sahajwalla, O. Ostrovski, Ironmaking Steelmaking 27, 5 (2000) 367-372.

[5] N. Eustathopoulos, M. G. Nicholas, B. Drevet, "Wettability at high temperatures", Pergamon, Amsterdam, The Netherlands 349 (1999) 13-51.

[6] J. J. Eksteen, Miner. Eng. 24, 7 (2011) 676-687.

[7] W. E. Lee, S. Zhang, VII Int. Conf. Molten Slags Fluxes and Salts, SAIMM (2004) 309-319.

[8] D. Bruce, R. Mera, D. Leatherdale, M. Taylor, R. Musgrove, "Techniques for characterising the wetting, coating and spreading of adhesives on surfaces", NPL Report DEPC MPR 020 (2005) 1-40.

[9] B. J. Keene, Contact angle and work of adhesion between ferrous melts and non-metallic solid, Slag Atlas $2^{\text {nd }}$ Ed., V. D. Eisenhüttenleute, (Ed.), Germany (1995) 513-517.

[10] M. Rigaud, "Corrosion of refractories and ceramics", Uhlig's Corrosion Handbook 51 (2011) 387-398. (Rec. 14/10/2014, Ac. 15/01/2015) 